\section{Salinity Tolerance of Muntries (Kunzea pomifera F. Muell.), a Native Food Crop in Australia}

\author{
Chi M. Do, Kate L. Delaporte, Vinay Pagay, and Carolyn J. Schultz ${ }^{1}$ \\ School of Agriculture, Food and Wine, Waite Research Institute, The \\ University of Adelaide, PMB1, Glen Osmond, SA, 5064, Australia
}

Additional index words. alternative fruits, homeostasis, potassium, salinity stress, sodium chloride, sustainable agriculture

\begin{abstract}
Identifying productive food crops that tolerate moderate soil salinity is critical for global food security. We evaluate the salinity tolerance of Kunzea pomifera (muntries), a traditional Indigenous food plant that grows naturally in coastal regions of southern Australia and thrives on relatively low rainfall. A range of saline irrigation treatments were tested on four genotypes: tap water, 50, 200, 300, and $400 \mathrm{mM} \mathrm{NaCl}$ [Maarten's Favorite (MF)] and up to $200 \mathrm{~mm} \mathrm{NaCl}$ (MP1, SES2, and CJ1). After a 10week saline irrigation treatment at $50 \mathrm{~mm} \mathrm{NaCl}$, SES2 appeared to have the highest salt tolerance of all genotypes based on no significant change in the number of secondary branches. At $50 \mathrm{~mm} \mathrm{NaCl}$, sodium accumulated significantly in roots but not the leaves of three genotypes, suggesting an active shoot exclusion mechanism. At $200 \mathrm{~mm} \mathrm{NaCl}$, plant growth decreased, $\mathrm{Na}^{+}$and $\mathrm{Cl}^{-}$generally accumulated to significantly higher levels in leaves, compared with $50 \mathrm{~mm} \mathrm{NaCl}$, whereas potassium $\left(\mathrm{K}^{+}\right)$levels were unchanged. At high $\mathrm{NaCl}(300$ and $400 \mathrm{~mm}$ ), $\mathrm{MF}$ showed severe growth retardation with leaf symptoms appearing in week 9. Our results indicate that two genotypes of $K$. pomifera, SES2 and $\mathrm{CJ} 1$, are moderately salt tolerant based on modest reductions in three growth parameters at $50 \mathrm{~mm} \mathrm{NaCl}$, compared with MF and MP1. Further evaluation of the natural diversity of this species should reveal a range of diverse mechanisms of salinity tolerance thus providing a new fruit crop for moderately saline soils. Chemical names: $\mathrm{NaCl}$ (sodium chloride).
\end{abstract}

Approximately 800 million ha worldwide are affected by saline soils (salinity) (FAO, 2016) caused by both natural processes over long periods of time and more rapidly by human practices such as land clearing, changing cropping systems, and irrigation (Parihar et al., 2015). In Australia, $\approx 5.7$ million ha had high salinity levels in 2000 , and it is estimated that this number will triple to $\approx 17$ million ha by 2050 , with 11 million ha of agricultural land affected (Australian Bureau of Statistics, 2010). Globally, salinity is responsible for economic losses with nominal values of \$27.3 billion (Qadir et al., 2014) and yield losses as high as $80 \%$ for some crops

Received for publication 7 June 2018. Accepted for publication 27 Aug. 2018.

This work was supported by Glenn and Joan Dennis (Mt Pleasant, South Australia) and Ray and Pat Rogers (McLaren Flat, South Australia) who generously provided their knowledge and time and allowed us to conduct this research using propagation material from their orchards. We thank Maarten Ryder and Michelle Wirthensohn for insightful comments on the manuscript. Chi M. Do is recipient of a joint Vietnam International Education Department and the University of Adelaide scholarship.

${ }^{1}$ Corresponding author. E-mail: carolyn.schultz@ adelaide.edu.au.

This is an open access article distributed under the CC BY-NC-ND license (http://creativecommons. org/licenses/by-nc-nd/4.0/).
When crops are subjected to soil salinity levels exceeding their tolerance levels, plant growth declines and crop yields decrease. For example, strawberry (sensitive) exhibits a reduced number of leaves and leaf area at $30 \mathrm{~mm} \mathrm{NaCl}$ and a $20 \%$ reduction in fruit yield (Garriga et al., 2015). A significant decrease in growth of date palm (tolerant) is observed at $7.3 \mathrm{dS} \cdot \mathrm{m}^{-1}$, and fruit yield is reduced by $\approx 25 \%$ (Department of Agriculture and Food, 2016). Olive is an example of a moderately tolerant fruit crop that shows relatively minor impacts at high salinity (7.5 $\mathrm{dS} \cdot \mathrm{m}^{-1}$ ), with $\approx 20 \%$ to $30 \%$ reduction in oil and fresh-fruit yield compared with nonsaltstressed plants (Al-Rawi and Al-Mohemdy, 2001). In citrus (lime and lemon, both sensitive crops), moderate salinity $(50 \mathrm{~mm} \mathrm{NaCl})$ reduces leaf number, area, and thickness by $\approx 20 \%$ (Alireza et al., 2013).

In addition to changes in growth parameters, many plants show changes in ion accumulation in roots and/or leaves or shoots, with contrasting trends for sodium and potassium accumulation. There is evidence that reduced levels of $\mathrm{K}^{+}$have a negative impact on stomatal function (Andres et al., 2014; Barragán et al., 2012; Liu et al., 2000) and many other physiological processes (Shabala and Pottosin, 2014).

Assessing genotypic variability for salinity tolerance is a key approach to identifying the most saline tolerant lines for existing and new crops. Salt tolerant genotypes of existing crops, such as wheat (Munns et al., 2012) and strawberries ( $F$. chiloensis f. patagonica) (Garriga et al., 2015), have been identified by screening wild accessions. Other efforts to increase global food security include identifying new crops that can grow productively under saline conditions, such as quinoa (Chenopodium quinoa) and saltbushes (Atriplex sp.) (Jacobsen et al., 2012).

One crop plant that has not yet been assessed for salinity tolerance is Kunzea pomifera (muntries; Myrtaceae), one of 13 key Australian native food crops (Clarke, 2013; Do et al., 2017; Sultanbawa, 2016). $K$. pomifera produces berries called muntries that are naturally sweet, contain high levels of antioxidants, and have high consumer acceptance in a range of products (Schultz et al., 2009). K. pomifera grows naturally in coastal regions of South Australia and Victoria, Australia (Ryder et al., 2008). Although the commercial production industry of muntries is still in its infancy, several plant selections have been made and are currently growing in orchards in South Australia. A recent study of plants at two orchards identified 15 unique genotypes and demonstrated high DNA sequence divergence between these selections (Do et al., 2018). K. pomifera is assumed to have a degree of tolerance to salt spray based on its ability to consistently produce fruit in "front-line" coastal environments that occur within their natural range; however, its tolerance to saline irrigation water is unknown. Salinity assessment of $K$. pomifera plants was listed as a research priority in a recent evaluation of the Australian 
native food industry (Clarke, 2012). The aims of this study were to establish a reference point for salt stress in $K$. pomifera. We did this by investigating the tolerance of four genotypes of $K$. pomifera to a broad range of soil salinity levels and assessing physiological performance. The analyses provide information on potential mechanisms of salinity tolerance in $K$. pomifera.

\section{Materials and Methods}

Design of experiments. A pilot experiment was conducted to establish methods and appropriate application of saline irrigation solutions; two genotypes of $K$. pomifera were tested, Maarten's Favorite (MF) and MP1. Plants, in draining pots, were irrigated with tap water ("control"), 50, 100, and $200 \mathrm{~mm}$ $\mathrm{NaCl}$. No growth parameters were measured and only EC (1:5) of potting mix and $\mathrm{Na}^{+}$and $\mathrm{K}^{+}$content of leaves and roots are reported (see Results). Two experiments were subsequently conducted in parallel using four diverse plant genotypes: MF, MP1, SES2, and CJ1 (Do et al., 2018). Expt. 1 evaluated an expanded range of physiological and morphological responses of MF plants to a broad range of salinity treatments (control, $50,200,300$, and $400 \mathrm{~mm} \mathrm{NaCl}$ ). Expt. 2 compared the same responses of different plant genotypes (MP1, SES2, and CJ1) treated with tap water (control) and 50 and $200 \mathrm{~mm} \mathrm{NaCl}$, except for CJ1 where no control treatment was performed because insufficient plants were available, and it was assumed that the other genotypes would provide approximate control values. All experiments were conducted in a glasshouse (South Australia Research Development Institute) at $23 \pm 3{ }^{\circ} \mathrm{C}$ with three to five pots per treatment and one plant per pot (Pilot Experiment, $n=4-5$; Expts. 1 and 2, $n=3-5$ ).

Plant propagation and establishment. Plants were propagated from 3- to $5-\mathrm{cm}$ vegetative cuttings; two plant genotypes, MP1 and MF, were propagated by a commercial nursery (State Flora, South Australia), whereas the SES2 and CJ1 genotypes were propagated in the experimental glasshouse. All plants were $\approx 2$ years old at the time of the experiment. These genotypes were chosen because they are genetically diverse (Do et al., 2018) and differ in a variety of horticultural traits, flavor (MF and MP1), and large fruit size (SES2), whereas CJ1 is a small fruited, recent selection from a coastal exposure in a low rainfall area of South Australia (Do et al., 2018).

To obtain plants with high uniformity (Expts. 1 and 2), all plants were pruned to one or two main stems (20-25 cm long), each having 2 to 4 primary branches $(5$ to $10 \mathrm{~cm}$ long) and repotted into round free-draining plastic pots (diameter $120 \mathrm{~mm}$ and height $150 \mathrm{~mm}$ ). Plants for the pilot experiment were also repotted $(90 \times 90 \mathrm{~mm}$ crosssection and height $180 \mathrm{~mm}$ ) but were pruned less (retaining up to five main stems and 70 $90 \mathrm{~cm}$ of each stem). Plants were grown for $\approx 3$ months. Potting mix used was Bio Gro
"6 mm Premium" (Mount Gambier, South Australia) with the following composition: fine lime $\left(2.0 \mathrm{~kg} \cdot \mathrm{m}^{-3}\right)$, dolomite $\left(1.0 \mathrm{~kg} \cdot \mathrm{m}^{-3}\right)$, gypsum $\left(1.0 \mathrm{~kg} \cdot \mathrm{m}^{-3}\right)$, potassium nitrate $(0.4$ $\left.\mathrm{kg} \cdot \mathrm{m}^{-3}\right)$, copper sulphate $\left(0.03 \mathrm{~kg} \cdot \mathrm{m}^{-3}\right)$, superphosphate $\left(0.5 \mathrm{~kg} \cdot \mathrm{m}^{-3}\right)$, ferrous sulphate $\left(0.5 \mathrm{~kg} \cdot \mathrm{m}^{-3}\right)$, urea $\left(0.2 \mathrm{~kg} \cdot \mathrm{m}^{-3}\right)$, micromix 240 $\left(0.3 \mathrm{~kg} \cdot \mathrm{m}^{-3}\right)$, Osmoform 38N-400102 (ICL Specialty Fertilizers, $0.5 \mathrm{~kg} \cdot \mathrm{m}^{-3}$ ), Osmoform NXT 4003 (ICL Specialty Fertilizers, 0.75 $\mathrm{kg} \cdot \mathrm{m}^{-3}$ ), 3- to 4-month Osmocote exact mini 16-3.5-9.1 + TE (ICL Specialty Fertilizers, $\left.2.5 \mathrm{~kg} \cdot \mathrm{m}^{-3}\right)$, Kwik-Wet $225\left(1 \mathrm{~kg} \cdot \mathrm{m}^{-3}\right)$, with $\mathrm{pH} \quad 6.2$ and EC $1.2 \mathrm{dS} \cdot \mathrm{m}^{-1}$. Additionally, Wettasoil (Amgrow, Lidcome, Australia) was applied $\approx 1$ week before $\mathrm{NaCl}$ treatments.

$\mathrm{NaCl}$ treatments. Irrigation solutions of tap water (control) and up to $200 \mathrm{~mm} \mathrm{NaCl}$ were applied directly to the plants each time (2-3 times per week and $250 \mathrm{~mL}$ saline solution per plant) for a 10 -week period (Pilot: 3 Mar. 2016 to 10 May 2016; Expts. 1 and 2: 17 July 2016 to 26 Sept. 2016). For treatments of 300 and $400 \mathrm{~mm} \mathrm{NaCl}$ applied to MF only, an incremental concentration was applied to minimize osmotic shock. For the treatment of $300 \mathrm{~mm} \mathrm{NaCl}, 200 \mathrm{~mm} \mathrm{NaCl}$ was applied for week 1 , while $300 \mathrm{~mm} \mathrm{NaCl}$ was applied from week 2 to week 10 . For the treatment with $400 \mathrm{~mm} \mathrm{NaCl}, 200$ and $300 \mathrm{~mm} \mathrm{NaCl}$ were applied to plants in weeks 1 and 2, respectively, and $400 \mathrm{~mm} \mathrm{NaCl}$ was applied to plants in weeks 3 to 10. Electrical conductivity $\left(\mathrm{EC}_{1: 5}\right)$ of tap water was 0.8 $\mathrm{dS} \cdot \mathrm{m}^{-1}(\approx 10 \mathrm{~mm}$ equivalent $\mathrm{NaCl})$, and the solutions with additional $\mathrm{NaCl}(50,100,200$, 300 , and $400 \mathrm{~mm} \mathrm{NaCl}$ ) measured 5.2, 8.9, $17.8,25.2$, and $33.8 \mathrm{dS} \cdot \mathrm{m}^{-1}$, respectively.

Measurements of relative growth reduction in plant genotypes. Vegetative growth of plants was measured at week 9 of the 10-week saline irrigation treatment (Expts. 1 and 2 only). Plant growth parameters measured consisted of the length of the longest main stem, the number of $1^{\circ}$ branches containing $2^{\circ}$ branches, and the number of $2^{\circ}$ branches (Fig. 1). Relative growth reduction (\%) was calculated as the mean of each of the indicated growth parameters $(50 \mathrm{~mm} \mathrm{NaCl})$ compared with controls $\{100-[100 \times$ mean (measurement at $50 \mathrm{~mm} \mathrm{NaCl}$ )/mean (measurement of the control)] \} (Obermeier et al., 2013). The assessment of sensitivity of relative growth $(\%)$ was based on Cassaniti et al. (2009), although the applied treatments were slightly different: sensitive genotypes ( $\geq 75 \%$ growth reduction); moderately sensitive genotypes (between $50 \%$ and $75 \%$ growth reduction); moderately tolerant genotypes (between $25 \%$ and $50 \%$ growth reduction) and tolerant genotypes ( $\leq 25 \%$ growth reduction).

Determination of chlorophyll content. Chlorophyll content was determined in week 9 of the 10 -week saline irrigation treatment (Expts. 1 and 2 only) using a SPAD meter (Model 502Plus; Konica Minolta Sensing Inc.) with auto calibration settings.

Collection of shoot and root material for ion analysis. Subsamples of shoots and roots were collected separately for each plant. Five to 10 shoots $(5-10 \mathrm{~cm}$ each) per plant were

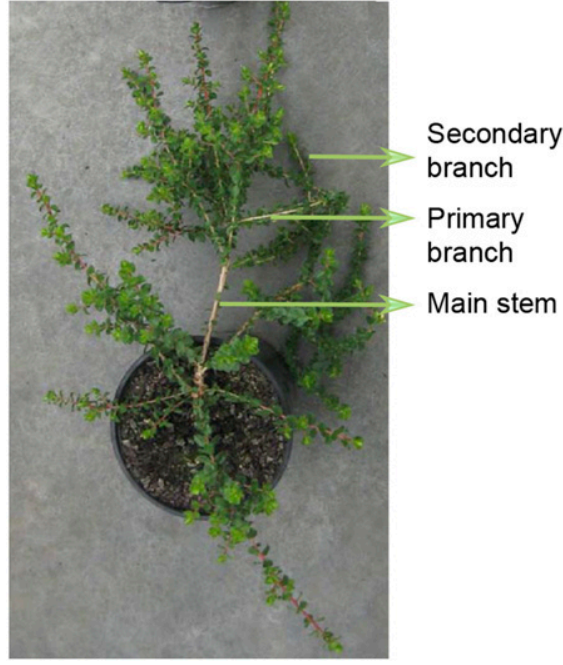

Fig. 1. Plant growth parameters: main stem, primary $\left(1^{\circ}\right)$ branches and secondary $\left(2^{\circ}\right)$ branches.

collected for fresh weight determination before separating into leaves and stems. Fresh weights were recorded and leaves and stems were dried separately at $65{ }^{\circ} \mathrm{C}$ for 2 to $3 \mathrm{~d}$ until constant weight.

For root samples, potting mix was removed as much as possible. A subsample of roots was collected and washed using tap water, then rinsed using reverse osmosis water. Roots were placed on filter papers (No. 5, Whatman) for 3 to $5 \mathrm{~h}$ at ambient temperature until no water was left on the filter paper. Fresh weights were recorded and the roots were then dried at $65^{\circ} \mathrm{C}$ for 2 to $3 \mathrm{~d}$ until no weight change was observed.

Determination of $\mathrm{Na}^{+}$and $\mathrm{K}^{+}$content. Approximately $0.1 \mathrm{~g}$ of dried leaves and roots were digested into $10 \mathrm{~mL} 1 \% \mathrm{HNO}_{3}$. The samples were incubated at $80{ }^{\circ} \mathrm{C}$ overnight (Berger et al., 2012). The digested samples were diluted 1:30 and 1:40 with Milli-Q water for samples of leaves and roots, respectively. The diluted samples were used to determine sodium and potassium levels using a flame photometer (Model 420; Sherwood, UK). The results were calculated as micromoles per gram dry weight $\left(\mu \mathrm{mol} \cdot \mathrm{g}^{-1}\right.$ DW) using a calibration curve generated from $5.8,11.7,17.4,23.2,29.0$, and 34.8 $\mathrm{mg} \cdot \mathrm{L}^{-1} \mathrm{NaCl}$.

Measurement of $\mathrm{Cl}^{-}$content. $\mathrm{Cl}^{-}$content was determined using the method of Munns (2010) with modification for a smaller volume, as follows. Mercuric thiocyanate $[\mathrm{Hg}$ $\left.(\mathrm{SCN})_{2}, 0.834 \mathrm{~g}\right]$ was dissolved in $100 \mathrm{~mL}$ methanol, then diluted with $200 \mathrm{~mL}$ methanol. The solution of $\mathrm{Hg}(\mathrm{SCN})_{2}$ was mixed well before filtering (No. 5 Whatman). Ferric nitrate $\left[\mathrm{Fe}\left(\mathrm{NO}_{3}\right)_{3} \cdot 9 \mathrm{H}_{2} \mathrm{O}, 40.4 \mathrm{~g}\right]$ was dissolved in $100 \mathrm{~mL}$ distilled water, then concentrated $\mathrm{HNO}_{3}(5 \mathrm{~mL})$ was added into the ferric nitrate solution before diluting with Milli-Q water to $200 \mathrm{~mL}$ and mixed. The ferric nitrate solution was mixed well and filtered (No. 5 Whatman). One hundred fifty milliliters of mercuric thiocyanate solution was combined with the $150 \mathrm{~mL}$ ferric nitrate 
solution; the mix was then diluted to $1 \mathrm{~L}$ using distilled water. Finally, $1.5 \mathrm{~mL}$ of the diluted mercuric thiocyanate and ferric nitrate mix was combined with $50 \mu \mathrm{L}$ digested $1 \%$ $\mathrm{HNO}_{3}$ samples of leaves or roots and $450 \mu \mathrm{L}$ $1 \% \mathrm{HNO}_{3}$, and absorbance at $480 \mathrm{~nm}$ was determined using a spectrophotometer (CECIL Model 2000; Cambridge, UK). The results were calculated as micromoles per gram dry weight $\left(\mu \mathrm{mol} \cdot \mathrm{g}^{-1} \mathrm{DW}\right)$ using a calibration curve generated from 5, 20, 40, 80, and $140 \mathrm{mg} \cdot \mathrm{L}^{-1} \mathrm{NaCl}$.

Measurement of electrical conductivity $\left(E C_{1.5}\right)$ of potting mix. Approximately 120 to $150 \mathrm{~g}$ of potting mix was collected after removing roots. Fresh weight was recorded, and then the mix was dried at $80^{\circ} \mathrm{C}$ for 3 to $4 \mathrm{~d}$ until there was no change in weight. Ten grams of dried potting mix was mixed with $50 \mathrm{~mL}$ Milli-Q water before shaking at $200 \mathrm{rpm}$ for $1 \mathrm{~h} . \mathrm{EC}_{1: 5}$ was determined using an EC meter (SmartChemLab, TPS, Brendale, Australia) as per Imada et al. (2015).

Statistical methods. Data were analyzed using either a one-way or two-way analysis of variance for effects on different genotypes and $\mathrm{NaCl}$ treatments. Significance between means was compared using Tukey's multiple comparison test $(P<0.05)$. Linear regression was performed between the growth characteristics (mean values) and the $\mathrm{NaCl}$ concentration. $R^{2}$ and $P$ values are reported. GraphPad Prism version 7 for MS Windows was used for all calculations (GraphPad Software; La Jolla, CA).

\section{Results}

Pilot experiment: Evaluation of responses of $M F$ and MPI to saline irrigation (control, 50, 100, and $200 \mathrm{~mm} \mathrm{NaCl}$ ). Saline irrigation treatments applied to MF and MP1 plants resulted in an increase in $\mathrm{EC}_{1: 5}$ of the potting mix (Fig. 2A), suggesting the 10 -week $\mathrm{NaCl}$ treatment was effective in applying a salt stress. No leaf symptoms were observed in any of the plants. $\mathrm{Na}^{+}$accumulated in roots and leaves of both MF and MP1 genotypes, with leaf $\mathrm{Na}^{+}$increasing $\approx 8.1$-fold and 4.7fold at $200 \mathrm{~mm} \mathrm{NaCl}$ compared with the controls, respectively. Sodium accumulated to higher levels in roots of plants watered with $200 \mathrm{~mm} \mathrm{NaCl}$ (Fig. 2B). No significant decrease in leaf potassium was measured for either genotype, although a significant reduction in root potassium $(\approx 1.7$-fold $)$ was observed for both MF and MP1 at $200 \mathrm{~mm}$ $\mathrm{NaCl}$ compared with the controls (Fig. 2C). Thus, the pilot experiment demonstrated that the $200 \mathrm{~mm} \mathrm{NaCl}$ irrigation treatment applied a relatively mild salt stress, affecting leaf and root $\mathrm{Na}^{+}$levels, but not leaf $\mathrm{K}^{+}$, with both genotypes responding in a similar fashion.

To extend these preliminary findings, two parallel experiments were conducted, the first (Expt. 1) on a specific genotype, MF, with a broad range of saline irrigations, and the second, Expt. 2, which used three treatments (up to $200 \mathrm{~mm}$ ) and three genotypes (MP1, SES2, and CJ1). Insufficient plants were available to test all genotypes across the expanded range of $\mathrm{NaCl}$ concentrations.
Expt. 1: Evaluation of responses of $M F$ genotype to a broad range of saline irrigation (control, 50, 200, 300, and $400 \mathrm{~mm} \mathrm{NaCl}$ ). Growth of MF plants. Growth of MF genotype was inhibited in a $\mathrm{NaCl}$ concentrationdependent manner as shown in several growth parameters (Fig. $3 \mathrm{~A}-\mathrm{E}$ ). $\mathrm{EC}_{1: 5}$ of potting mix increased with increasing external $\mathrm{NaCl}$ treatments (mean \pm SD of $1.0 \pm 0.7$, $5.91 \pm 1.7,8.1 \pm 1.8,13.3 \pm 1.6$, and $14.1 \pm$ $1.4 \mathrm{dS} \cdot \mathrm{m}^{-1}$ for control, 50, 200, 300, and $400 \mathrm{~mm} \mathrm{NaCl}$ treatments, respectively), showing an opposite trend to plant growth (Fig. 3A-E). Plant growth and $\mathrm{EC}_{1.5}$ of the potting mix were negatively correlated (linear regression) with $R^{2}$ for main stem length $(0.79, P=0.043)$, the number of $1^{\circ}$ branches containing $2^{\circ}$ branches $(0.79, P=0.044)$ and the number of $2^{\circ}$ branches $(0.71, P=0.072)$. Plant growth reduced significantly when treated with $200 \mathrm{~mm} \mathrm{NaCl}$, compared with control plants, but declined more dramatically for all three growth parameters when plants were exposed to 300 and $400 \mathrm{~mm} \mathrm{NaCl}$ (Fig. 3A and C-E). Main stem length reduced 1.8-fold (Fig. 3A and C), and more dramatic reductions were observed in the number of $1^{\circ}$ branches containing $2^{\circ}$ branches $(7.0$-fold) (Fig. $3 \mathrm{~A}$ and $\mathrm{D}$ ) and the number of $2^{\circ}$ branches (8.0-fold) (Fig. 3A and E) between control plants and plants treated with the highest concentration of $\mathrm{NaCl}(400 \mathrm{~mm})$.

At week 9, most plants irrigated with $200 \mathrm{~mm} \mathrm{NaCl}$ had a few older leaves that were brown/pigmented on the main stem and primary branches, and the apical leaves were less expanded in all directions. At week 9, the MF plants treated with $300 \mathrm{~mm} \mathrm{NaCl} \mathrm{de-}$ veloped minor leaf symptoms, such as epinastic leaves ( $5 / 5$ plants) and red margins on the leaves of the primary apices $(5 / 5$ plants, Fig. 3F). At $400 \mathrm{~mm} \mathrm{NaCl}$ two plants had primary branches with leaves that looked dehydrated based on leaf color change from bright green to gray/green (Fig. 3G). In all plants, most of the leaves were still bright green, with no significant difference in relative water content $(\%, P=0.1069)$. A significant difference was detected in chlorophyll content $(P=0.0176)$, with a reduction in chlorophyll content (SPAD values) evident from the control treatment $(58.5 \pm 2.2)$ to the $400 \mathrm{~mm}$-treated plants $(51.3 \pm 3.5)$, although none of the pairs of means was statistically significant.

At week 10, some of the symptoms in the $400 \mathrm{~mm} \mathrm{NaCl}$-treated MF plants worsened, and two plants had primary stems that had died (Fig. 3H). The stress was so severe that approximately half the plants within each of the 300 and $400 \mathrm{~mm} \mathrm{NaCl}$ treatments died within 1 week of repotting following root harvesting and resumption of normal (nonsaline) watering, whereas most plants treated with 0,50 , and $200 \mathrm{~mm} \mathrm{NaCl}$ survived soil removal, root harvesting, and repotting (data not shown). Even at 50 and $200 \mathrm{~mm} \mathrm{NaCl}$, a noticeable decline in healthy white roots was evident when the pots were removed (Fig. 3I).

$\mathrm{Na}^{+}$and $\mathrm{Cl}^{-}$content in leaves and roots of $M F$. Sodium content increased in plant tis-
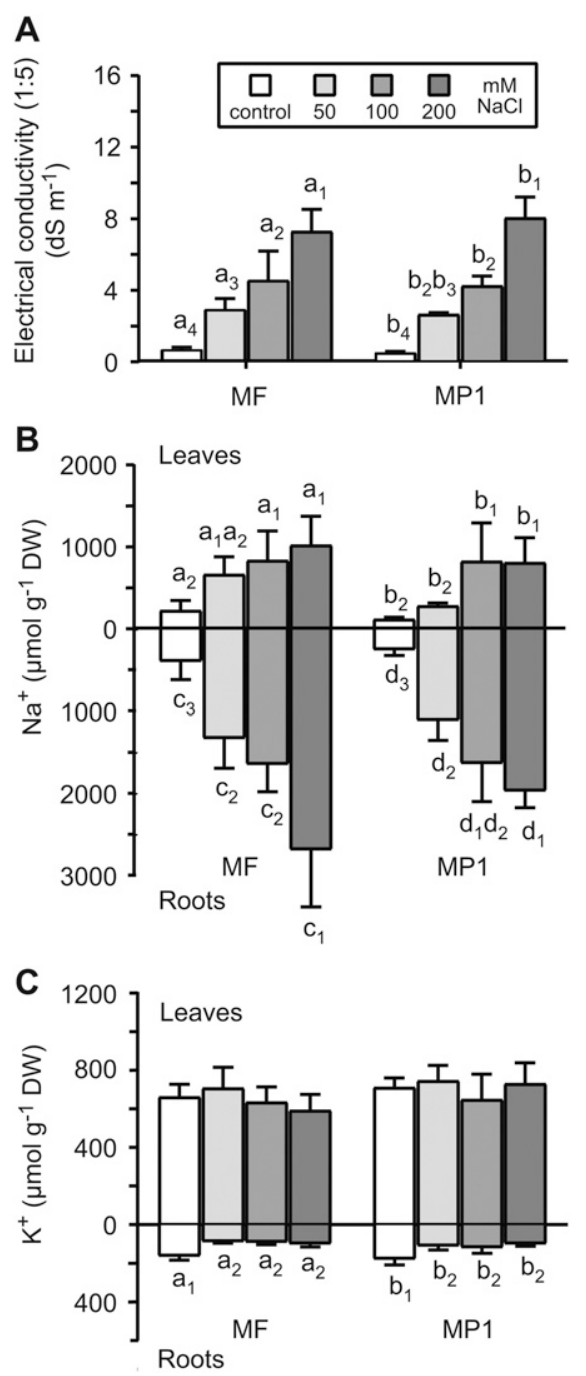

Fig. 2. The effect of $\mathrm{NaCl}$ treatment on potting mix salinity and cation content $\left(\mathrm{Na}^{+}\right.$and $\left.\mathrm{K}^{+}\right)$of two $K$. pomifera genotypes, MP1 and MF. $\mathrm{NaCl}$ treatments were control, 50, 100, and $200 \mathrm{~mm}$ $\mathrm{NaCl}$ corresponding to measured $\mathrm{EC}_{1.5}$ of irrigation solutions, $\approx 0.8,5.2,8.9$, and 17.8 $\mathrm{dS} \cdot \mathrm{m}^{-1}$, respectively. (A) Electrical conductivity (1:5) of potting mix $\left(\mathrm{dS} \cdot \mathrm{m}^{-1}\right)$ and concentrations $\left(\mu \mathrm{mol} \cdot \mathrm{g}^{-1} \mathrm{DW}\right)$ of $(\mathbf{B}) \mathrm{Na}^{+}$and $(\mathbf{C}) \mathrm{K}^{+}$ in leaves and roots (above and below the $x$ axis, respectively). Data are means of four to five replicates \pm SD. Letters (a different one for each genotype and tissue) are used to indicate different tests and subscripted numbers are used to indicate significant differences among treatments according to Tukey's multiple comparison test $(P \leq 0.05)$.

sues under saline conditions (Fig. 3J). Plants treated with the highest salinity concentration $(400 \mathrm{~mm} \mathrm{NaCl})$ accumulated significantly more $\mathrm{Na}^{+}$than control plants, and the fold change in leaves (29.8-fold) was greater than the fold change in roots (4.5-fold) (Fig. 3J). No significant difference in $\mathrm{Na}^{+}$levels was observed in leaf and roots of plants grown at 50, 200, and $300 \mathrm{~mm} \mathrm{NaCl}$ (Fig. 3J).

A similar increasing trend was observed in the chloride content in leaves and roots at different levels of salinity stress (Fig. 3K). Chloride content in leaves and roots increased in plants treated with $400 \mathrm{~mm} \mathrm{NaCl}$, 

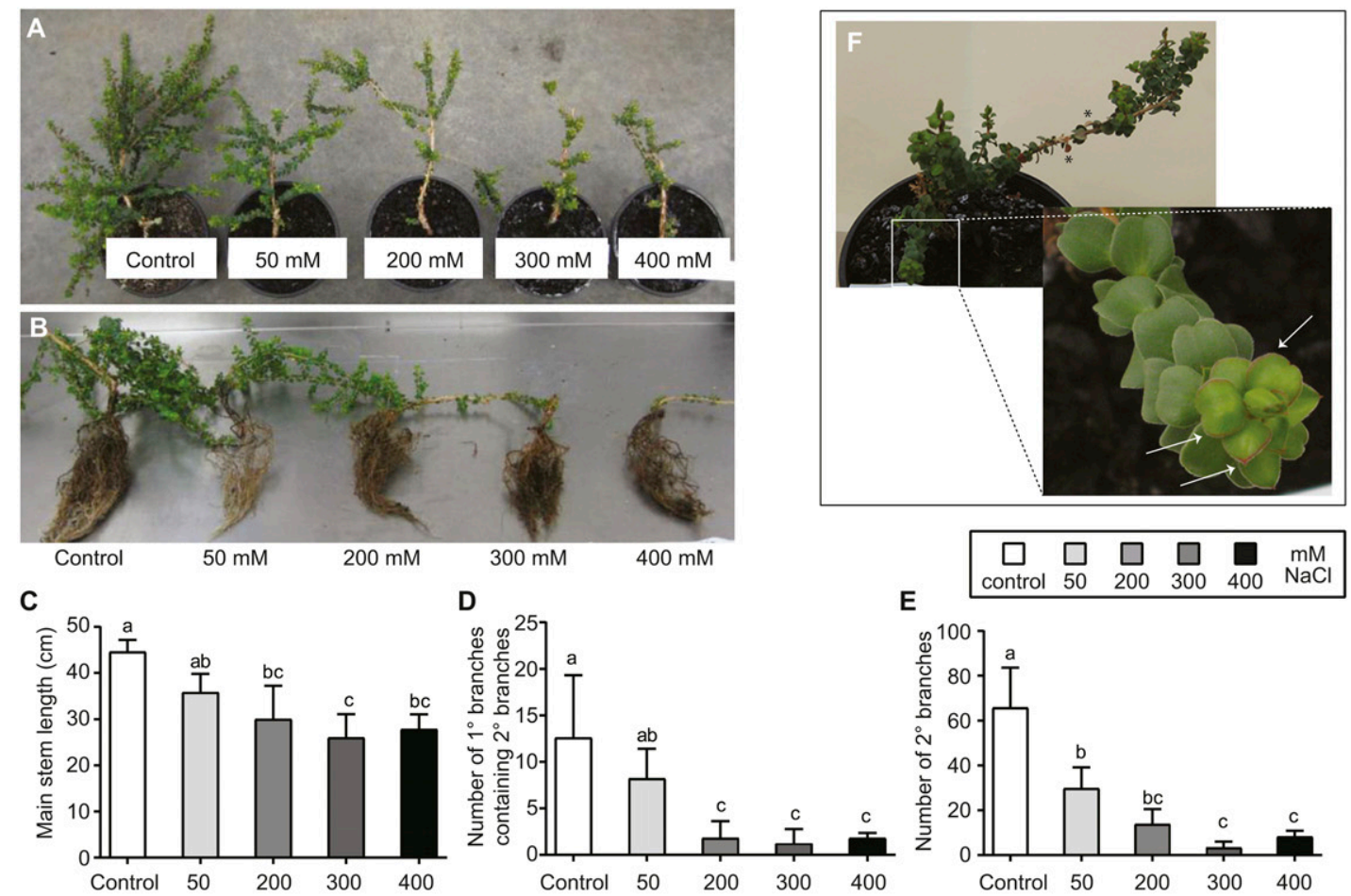

D
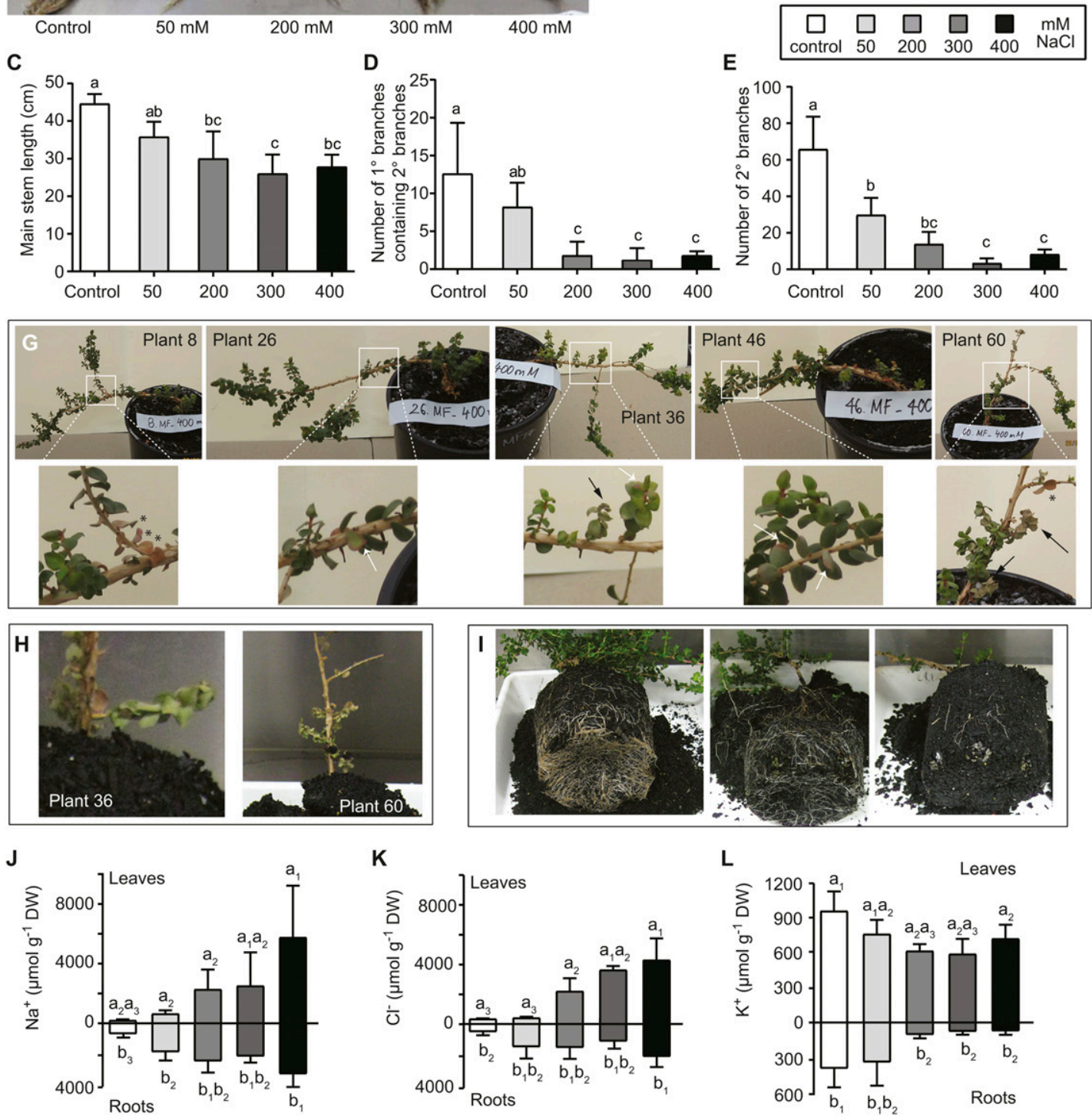

Fig. 3. Response of $K$. pomifera MF plants to a broad range of saline irrigation treatments. (A) MF plants in pots at week 9 of a 10 -week treatment (control, $50,200,300$, and $400 \mathrm{~mm} \mathrm{NaCl}$ treatments). (B) $\mathrm{MF}$ plants after removing potting mix, (C) main stem length, (D) number of $1^{\circ}$ branches containing $2^{\circ}$ branches, (E) number of $2^{\circ}$ branches, $(\mathbf{F})$ plant 21 at Week $9(300 \mathrm{~mm} \mathrm{NaCl}$ treated, inset with close-up of leaf symptoms), (G) five plants from the $400 \mathrm{~mm} \mathrm{NaCl}$ treatment (week 9 , with close-up of leaf symptoms below), (H) two plants at week 10 of $400 \mathrm{~mm} \mathrm{NaCl}$ treatment (harvest), (I) root growth before removal of potting media, and content ( $\left.\mu \mathrm{mol} \cdot \mathrm{g}^{-1} \mathrm{DW}\right)$ of $(\mathbf{J}) \mathrm{Na}^{+},(\mathbf{K}) \mathrm{Cl}^{-}$, and $(\mathbf{L}) \mathrm{K}^{+}$in leaves and roots (above and below the $\mathrm{X}$ axis, respectively) of MF plants after 10 weeks of treatment. Data are means of three to five replicates \pm sD. Letters above the bars $(\mathbf{C}-\mathbf{E})$ indicate significant differences among treatments according to Tukey's multiple comparison test $(P \leq$ 0.05). In $\mathbf{F}$ and $\mathbf{G}$, white arrows indicate leaves with symptoms on the margins, $*$ indicates dead leaves, and black arrows indicate dehydrated/graying leaves. In $\mathbf{J}-\mathbf{L}$, letters a (for shoots) and b (for roots) are used to indicate different tests, and subscripted numbers are used to indicate significant differences among treatments.

13.7-fold (from $306 \pm 50.2$ to $4182 \pm 1442$ $\mu \mathrm{mol} \cdot \mathrm{g}^{-1} \mathrm{DW}$ in leaves) and 5.4-fold (from $387.6 \pm 294.3$ to $2102 \pm 715.3 \mu \mathrm{mol} \cdot \mathrm{g}^{-1} \mathrm{DW}$ in roots) compared with control plants

HortScience Vol. 53(11) November 2018
(Fig. 3K). Chloride was $1.4 \times, 3.8 \times$, and $2.0 \times$ higher in leaves than in roots of plants exposed to 200, 300, and $400 \mathrm{~mm} \mathrm{NaCl}$, respectively.
$K^{+}$content in leaves and roots of $M F$ plants. $\mathrm{K}^{+}$decreased significantly in roots and leaves of MF with saline irrigation at $200 \mathrm{~mm} \mathrm{NaCl}$ and above (Fig. 3L). The $\mathrm{K}^{+}$ 
content of leaves and roots of plants exposed to $400 \mathrm{~mm} \mathrm{NaCl}$ reduced 0.7 -fold and 5.7fold, respectively, compared with control plants [reduced from $967.1 \pm 169.5$ to $713.8 \pm$ $121.2 \mu \mathrm{mol} \cdot \mathrm{g}^{-1} \mathrm{DW}$ (leaves) and from $394.0 \pm$ 164.4 to $69.0 \pm 34.1 \mu \mathrm{mol} \cdot \mathrm{g}^{-1} \mathrm{DW}$ (roots)] (Fig. 3L). The $\mathrm{K}^{+}$content of leaves and roots of plants grown at 200,300, and $400 \mathrm{~mm} \mathrm{NaCl}$ (Fig. 3L) was not significantly different.

In summary, increasing salinity resulted in significant changes in plant growth and ion accumulation in MF plants. Growth of MF plants dramatically declined at the highest salinity treatments of 300 and $400 \mathrm{~mm} \mathrm{NaCl}$. $\mathrm{Na}^{+}$and $\mathrm{Cl}^{-}$accumulated in both leaves and roots of MF plants whereas $\mathrm{K}^{+}$levels decreased, particularly in roots.

Expt. 2: evaluation of three additional $\mathrm{K}$. pomifera genotypes (MP1, SES2, and CJ1) with saline irrigation (control, 50, and $200 \mathrm{~mm} \mathrm{NaCl}$ ). Growth of MP1, SES2, and CJ1 plants. At $50 \mathrm{~mm} \mathrm{NaCl}$, the main stem length of all three genotypes was similar to the control plants (Fig. 4A). Stem length decreased 0.3 to 0.4 fold in MP1 and SES2 (from control to $200 \mathrm{~mm} \mathrm{NaCl}$ ) and 0.4-fold in $\mathrm{CJ} 1$ (from 50 to $200 \mathrm{~mm} \mathrm{NaCl}$ ) (Fig. 4A). Branching [number of primary $\left(1^{\circ}\right)$ branches containing secondary $\left(2^{\circ}\right)$ branches, and the number of $2^{\circ}$ branches] was inhibited with increasing salinity in most genotypes except for SES2 in the $50 \mathrm{~mm} \mathrm{NaCl}$ treatment. All three growth parameters remained relatively stable at $50 \mathrm{~mm} \mathrm{NaCl}$ in SES2 compared with controls (Fig. 4A-C), whereas a decrease was observed in the number of $1^{\circ}$ branches containing $2^{\circ}$ branches (Fig. 4B) and the number of $2^{\circ}$ branches for MP1 (Fig. 4C). At $200 \mathrm{~mm}$ $\mathrm{NaCl}$, the number of $1^{\circ}$ branches containing $2^{\circ}$ branches reduced $\approx 3$-fold for both MP1 and SES2 plants (compared with controls) and $\approx 2$-fold in CJ1 plants (compared with the $50 \mathrm{~mm} \mathrm{NaCl}$ treated plants) (Fig. 4B). The $\mathrm{EC}_{1: 5}$ of the potting mix increased with increasing concentration of $\mathrm{NaCl}$ in the irrigation water as expected. $\mathrm{EC}_{1: 5}$ values were consistent with those obtained in Expt. 1 (data not shown).

Content of $\mathrm{Na}^{+}, \mathrm{Cl}^{-}$and $\mathrm{K}^{+}$in plant tissues of MP1, SES2, and CJ1 genotypes. Treatment with $\mathrm{NaCl}$ resulted in a significant increase in $\mathrm{Na}^{+}$in the roots, compared with the controls, of MP1 at $200 \mathrm{~mm} \mathrm{NaCl}(\approx 1.9$-fold) and $\mathrm{SES} 2$ at $50 \mathrm{~mm} \mathrm{NaCl}(\approx 2.0$-fold) (Fig. 4D). The levels of $\mathrm{Na}^{+}$in the root of $\mathrm{CJ} 1$ at 50 and $200 \mathrm{~mm} \mathrm{NaCl}$ were similar to the levels of MP1. All three genotypes had a significant increase in $\mathrm{Na}^{+}$in the leaf at $200 \mathrm{mM} \mathrm{NaCl}$ compared with controls (MP1 and SES2) or $50 \mathrm{~mm} \mathrm{NaCl}$ (SES2 and CJ1) (Fig. 4D). For example, the increase in $\mathrm{Na}^{+}$content in leaves of plants grown at $200 \mathrm{~mm}$ compared with
$50 \mathrm{~mm} \mathrm{NaCl}$ was 3.1-fold, 7.0-fold, and 4.1fold higher for MP1, SES2, and CJ1, respectively (Fig. 4D).

The saline irrigation treatments also resulted in an increase in $\mathrm{Cl}^{-}$content in leaves of all three plant genotypes (Fig. 4E). CJ1 accumulated significantly more $\mathrm{Cl}^{-}$in leaves than MP1 at $200 \mathrm{~mm} \mathrm{NaCl}$ (Fig. 4E). In roots, there was a trend toward higher $\mathrm{Cl}^{-}$content in roots at $50 \mathrm{~mm} \mathrm{NaCl}$ (significant for SES2), but levels decreased (nonsignificantly) for all genotypes at $200 \mathrm{~mm} \mathrm{NaCl}$ (Fig. 4E).

In contrast to accumulation of $\mathrm{Na}^{+}, \mathrm{K}^{+}$ content decreased significantly in roots of MP1 and SES2 plants treated with $50 \mathrm{~mm}$ $\mathrm{NaCl}, \approx 3.4$-fold and 1.8-fold compared with control plants [from $517.7 \pm 5.3$ to $153.8 \pm$ 41.6 (MP1) and from $408.1 \pm 134.4$ to $223.4 \pm 76.6$ (SES2) $\mu \mathrm{mol} \cdot \mathrm{g}^{-1}$ DW]. Leaf $\mathrm{K}^{+}$content was significantly lower for SES2 at $50 \mathrm{~mm} \mathrm{NaCl}$ compared with the control plants, but for MP1 there was no significant difference (Fig. 4F). At $200 \mathrm{~mm} \mathrm{NaCl}, \mathrm{CJ} 1$ showed a different trend (an increase) in leaf $\mathrm{K}^{+}$ relative to $50 \mathrm{~mm} \mathrm{NaCl}$, and this response was significantly different from that of the other two genotypes (Fig. 4F).

On the basis of the modest percentage reduction in relative growth, SES2 and CJ1 may be considered moderately tolerant genotypes $(25.3 \%$ and $29.3 \%$ reduction in the
A

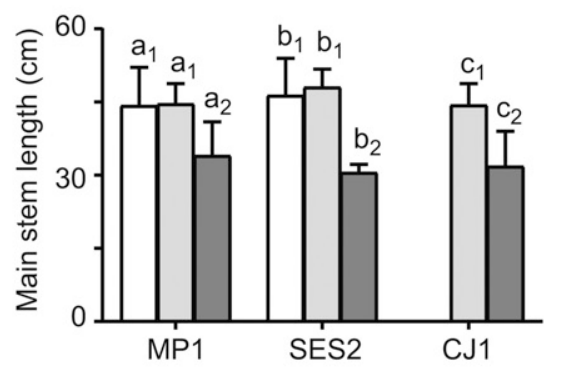

D

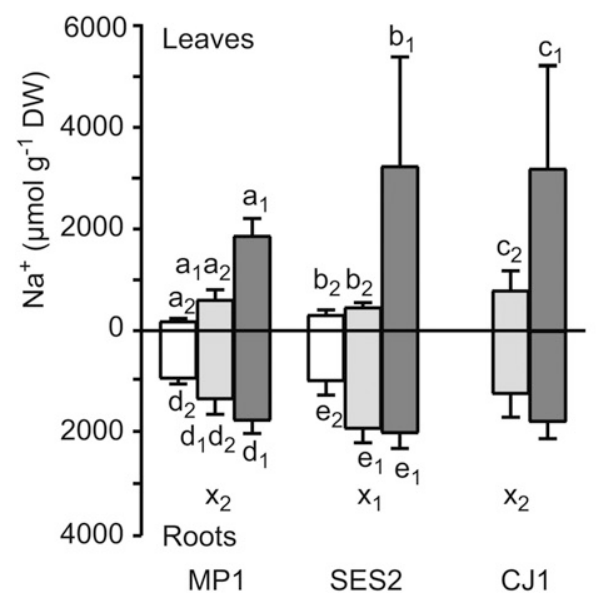

B

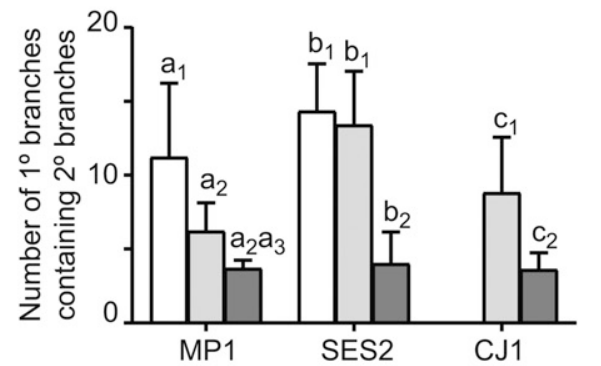

E

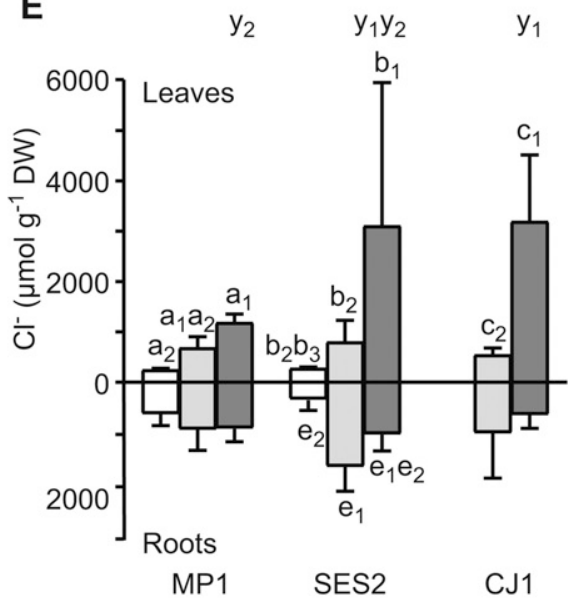

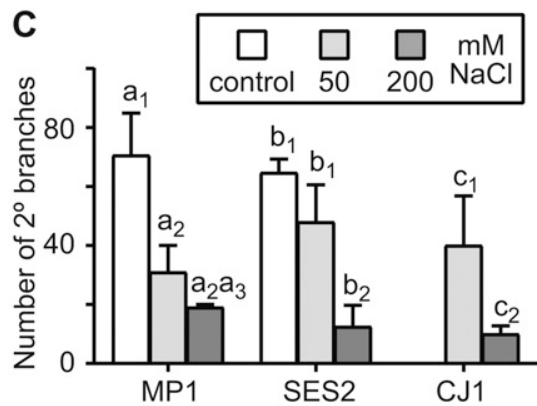

$\mathbf{F}$

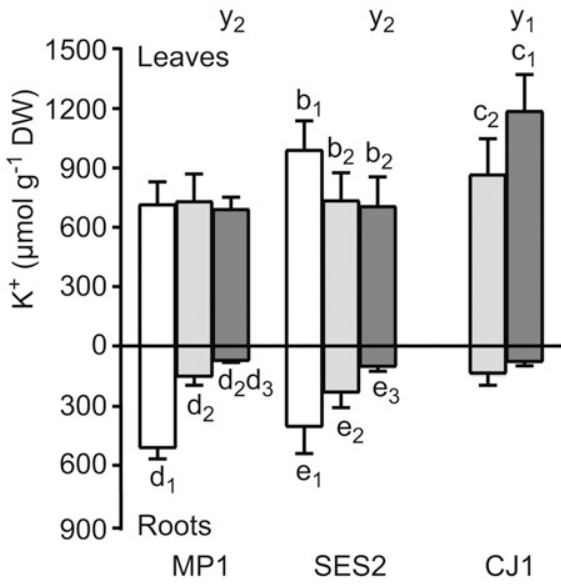

Fig. 4. Growth, development, and ion content $\left(\mathrm{Na}^{+}, \mathrm{Cl}^{-}\right.$, and $\left.\mathrm{K}^{+}\right)$of three $K$. pomifera genotypes in response to moderate salinity. (A) Main stem length, $(\mathbf{B})$ number of $1^{\circ}$ branches containing $2^{\circ}$ branches, $(\mathbf{C})$ number of $2^{\circ}$ branches, content $\left(\mu \mathrm{mol} \cdot \mathrm{g}^{-1} \mathrm{DW}\right)$ of $(\mathbf{D}) \mathrm{Na}^{+},(\mathbf{E}) \mathrm{Cl}^{-}$, and $(\mathbf{F}) \mathrm{K}^{+}$in leaves and roots $($above and below the X-axis, respectively) of MP1, SES2, and CJ1 plants after 10 weeks of treatment (control and 50 and $200 \mathrm{~mm} \mathrm{NaCl).} \mathrm{Data} \mathrm{are} \mathrm{means} \mathrm{of} \mathrm{three} \mathrm{to} \mathrm{five}$ replicates \pm SD. Letters (a different letter for each genotype/tissue combination) are used to indicate different tests and subscripted numbers are used to indicate significant differences between $\mathrm{NaCl}$ concentrations according to Tukey's multiple comparison test $(P \leq 0.05)$; $\mathrm{x}_{1}$ and $\mathrm{x}_{2}$ represent significant differences between plant genotypes at $50 \mathrm{~mm} \mathrm{NaCl}$ treatments and $\mathrm{y}_{1}$ and $\mathrm{y}_{2}$, between plant genotypes at $200 \mathrm{~mm} \mathrm{NaCl}$ treatments. 
number of $2^{\circ}$ branches, respectively), while MF1 and MP1 may be considered moderately sensitive genotypes $(55.7 \%$ and $59.3 \%$ reduction in the number of $2^{\circ}$ branches, respectively) (Table 1). Therefore, based on growth parameters, the salinity tolerance of four $K$. pomifera genotypes may be ranked as $\mathrm{SES} 2 \approx \mathrm{CJ} 1>\mathrm{MF} \approx \mathrm{MP} 1$.

\section{Discussion}

These experiments have evaluated the salinity tolerance of four $K$. pomifera genotypes. The findings suggest that genotypic variation exists for traits that are responsive to saline irrigation in this small yet genotypically diverse sample.

Reduction in plant growth. Because there are limited reports of quantitative growth assessment of $K$. pomifera either in the field or in pots (Page, 2004), it was necessary to decide which characteristics to measure. At low, moderate, and high salinity levels (control, 50 and $200 \mathrm{~mm}$, respectively), reductions in three traits were observed: main stem length, number of $1^{\circ}$ branches containing $2^{\circ}$ branches, and number of $2^{\circ}$ branches (Figs. 3C-E and 4A-C). This study showed that the number of $2^{\circ}$ branches was the most responsive parameter to increasing saline irrigation based on a significant reduction in two genotypes at $50 \mathrm{~mm} \mathrm{NaCl}$ (MF and MP1), followed by the number of $1^{\circ}$ branches containing $2^{\circ}$ branches (significant reduction in MP1 at $50 \mathrm{~mm} \mathrm{NaCl}$ ), and main stem length (significant reduction in all four genotypes at $200 \mathrm{~mm} \mathrm{NaCl}$ ) (Figs. 3C-E and 4A-C). Other growth traits were measured, including number of $1^{\circ}$ branches, number of freshly emerged leaves, length of $1^{\circ}$ branches and of $2^{\circ}$ branches; these parameters were either not significant (number of $1^{\circ}$ branches) or were difficult to measure objectively.

Growth reductions during the ionaccumulation independent phase have two broad consequences: reduction in cell division and cell elongation (Fricke and Peters, 2002; Passioura and Munns, 2000). To determine which processes are affected in saline-treated $K$. pomifera, future studies could measure internode length on the main stem (Abassi et al., 2014) and epidermal cell size (Wu et al., 2015).

On the basis of the categories of relative tolerance of plants to saline water (see Introduction) and compared with other fruit crops grown in these salinity ranges, $K$. pomifera may be considered moderately tolerant to salinity (up to $50 \mathrm{~mm} \mathrm{NaCl}$ ) as the three growth parameters in SES2 and CJ1 remained relatively stable compared with the other genotypes [assuming that the estimated control value for CJ1 is realistic (see Table 1), which will need to be confirmed in future experiments]. At $200 \mathrm{~mm} \mathrm{NaCl}$, deleterious effects on growth parameters were observed across all genotypes, although MP1 had a slightly higher number of $2^{\circ}$ branches so could be considered more tolerant of higher levels of salinity.

Effect of salinity on accumulation of ions in $\mathrm{K}$. pomifera plant tissues. In all four $K$. pomifera genotypes, a similar accumulation pattern of $\mathrm{Na}^{+}$was observed under low and moderate salinity (control and $50 \mathrm{~mm} \mathrm{NaCl}$ ), where $\mathrm{Na}^{+}$mainly accumulated in roots (Figs. 3J and 4D) suggesting that both sodium exclusion and tissue tolerance (Munns and Tester, 2008) may be contributing to salinity tolerance in $K$. pomifera. At moderate salinity $(50 \mathrm{~mm} \mathrm{NaCl}), \mathrm{Na}^{+}$could be either maintained in root vacuoles, effluxed from cells to the apoplast, or excreted to the soil. If any or all of these situations occur, $\mathrm{Na}^{+}$ transport to leaves would be negligible, accounting for the low $\mathrm{Na}^{+}$content (not significantly different from the controls) in leaves relative to roots. However, at high salinity $(200 \mathrm{~mm} \mathrm{NaCl})$, the $\mathrm{Na}^{+}$levels in the shoots increase significantly, but the levels in roots remained relatively unchanged, and excess $\mathrm{Na}^{+}$was likely delivered to leaves through the transpiration stream. We therefore hypothesize that $\mathrm{Na}^{+}$is compartmentalized in leaf vacuoles to prevent high toxicity to the cytoplasm (Munns and Tester, 2008; Roy et al., 2014) because only minor leaf symptoms were observed at $200 \mathrm{~mm} \mathrm{NaCl}$.

At the highest salinity levels in this trial (300 and $400 \mathrm{~mm} \mathrm{NaCl}$ ), $\mathrm{Na}^{+}$accumulated to higher levels in leaves compared with roots of MF plants $[\approx 1.2$-fold higher $(300 \mathrm{~mm})$ and 1.9-fold higher $(400 \mathrm{~mm})]$, whereas the ratio at high salinity $(200 \mathrm{~mm} \mathrm{NaCl})$ was $\approx 0.76$. At extremely high salinity levels, plants developed yellow-brown senescent leaves at the end of week 9, and the MF plants deteriorated quickly in week 10 of $\mathrm{NaCl}$ application, with leaf drop producing leafless regions of stem (Fig. 3G and H). Future efforts to identify genotypes that are more salt tolerant than SES2 and CJ1 should consider measuring different traits such as leaf color (yellow/ brown), epinasty, and length of leafless stems (due to leaf loss) when $K$. pomifera is exposed to high salinity levels.

Maintaining potassium homeostasis in the cytoplasm is vital to avoid sodium toxicity

Table 1. Relative growth reduction (\%) of $K$. pomifera genotypes exposed to $50 \mathrm{~mm} \mathrm{NaCl}$ compared with nonsalt-treated K. pomifera. $^{\text {z }}$

\begin{tabular}{lccc}
\hline & \multicolumn{3}{c}{ Relative growth reduction at $50 \mathrm{~mm} \mathrm{NaCl} \mathrm{( \% )}$} \\
\cline { 2 - 4 } Genotype & Main stem length & $1^{\circ}$ branches with $2^{\circ}$ branches & No. $2^{\circ}$ branches \\
\hline MF & $\mathbf{1 9 . 7}$ & 34.9 & 55.7 \\
MP1 & $\mathbf{0 . 0}$ & 44.6 & 59.1 \\
SES2 & $\mathbf{0 . 0}$ & $\mathbf{0 . 0}$ & $\mathbf{2 5 . 3}$ \\
CJ1 & $\mathbf{1 . 4}$ & $\mathbf{1 4 . 2}$ & $\mathbf{2 9 . 3}$ \\
\hline
\end{tabular}

${ }^{\mathrm{z}}$ Calculation for each genotype and growth trait was $\{100-[100 \times$ mean (measurement at $50 \mathrm{~mm} \mathrm{NaCl})$ mean (measurement of the control)]\}. For CJ1, a control value was estimated from the mean control values of MF, MP1, and SES2. Bold indicates values where growth reductions are less than $30 \%$. and maintain cells with normal metabolism and functioning (Shabala and Pottosin, 2014). In this study, the higher $\mathrm{K}^{+}$content in leaves compared with roots could be due to a homeostasis of $\mathrm{K}^{+}$in leaves. One genotype (MP1) maintained stable leaf $\mathrm{K}^{+}$content at $200 \mathrm{~mm} \mathrm{NaCl}$, two genotypes had a modest decrease in leaf $\mathrm{K}^{+}$(MF and SES2), and one genotype had an increased $\mathrm{K}^{+}$content $(\mathrm{CJ} 1)$ (Figs. 3I and 4F). The mostly stable $\mathrm{K}^{+}$ content in leaves of $K$. pomifera indicates active transport of $\mathrm{K}^{+}$from roots to shoots as has been suggested for Juncus spp. (Al Hassan et al., 2016). More evidence for leaf $\mathrm{K}^{+}$homeostasis was observed in the pilot experiment, where plants with more canopy (less severely pruned) were used. Plants in the pilot experiment were multistemmed as observed in natural environments, and this apparently provided a sodium dilution effect because leaf $\mathrm{Na}^{+}$accumulation was $\approx 2$-fold lower for multistemmed MF (Fig. 2A) compared with single-stemmed MF plants (Fig. 3J), and for multistemmed MP1 plants (Fig. 2A) compared with single-stemmed MP1 plants (Fig. 4D). Leaf $\mathrm{K}^{+}$was unchanged in the multistemmed MF plants, even at $200 \mathrm{~mm} \mathrm{NaCl}$ (Fig. 2C) compared with the significant $\mathrm{K}^{+}$reduction seen in single-stemmed MF plants (Fig. 3L). This suggests that plants in the field may be tolerant to higher levels of saline irrigation treatments than those grown in pots, which should be tested in the future.

A few comments are provided on the technical aspects of these experiments. Large error bars were observed in some experiments and we conclude that these were likely due to "real differences" in the tissues samples rather than low replication because the samples with the largest error bars, SES2 and CJ1, at $200 \mathrm{~mm}$ (Fig. 4D and E) had four and five replicates, respectively. One possible explanation for this is the use of a variable number of older and younger leaves between samples. This could be tested in the future by comparing the ion content of leaves on the main, primary and secondary stems, and ensuring that similar proportions of each are taken when sampling.

Another difference that could be implemented in future experiments would be to ensure that micronutrient activity is maintained by calculating the concentration of micronutrients needed to compensate for the impact of $\mathrm{NaCl}$ on for example calcium availability (Jha et al., 2010). This can be done using programs such as Visual Minteq Version 2.3 (KTH, Department of Land and Water Resources Engineering, Stockholm, Sweden). We elected not to do this in these experiments to mimic the effect of using saline groundwater, which is generally used as is.

An important consideration for future experiments is to measure the salinity of leachate at each watering to establish the soil salinity build up during the experiment. We allowed the salinity to build up during these experiments to mimic the effects of salt build during the hot, dry summers of southern Australia. New crops are often watered without consideration of the need for additional 
water to ensure that irrigation water reaches below the roots to prevent salt buildup in the root zone (Corwin and Grattan, 2018). K. pomifera plants in commercial orchards are susceptible to sudden "dieback" (Clarke, 2013), and it is possible that increased salinity could be a contributing factor, although the exact cause of dieback has not been investigated. The 10 -week salinity irrigation experiments here clearly show that root growth is reduced even at $50 \mathrm{~mm} \mathrm{NaCl}$ for MF (Fig. 3I), and similar reductions were seen for all genotypes. Although root traits were not quantified in these experiments, these should be considered in the future. Understanding the cause of $K$. pomifera dieback is of critical importance to the muntries industry as demand is now outstripping supply (Andrew Fielke, personal communication) and southern Australia is experiencing prolonged drought without summer rainfall that can flush salt buildup.

\section{Conclusions}

The present study documented the morphological and physiological responses of four K. pomifera genotypes to different $\mathrm{NaCl}$ irrigation treatments. This study established that genotypic differences exist for characteristics that are responsive to saline irrigation and established that two genotypes, SES2, and CJ1, are moderately tolerant to this stress. To identify $K$. pomifera genotypes with a broader range of salinity tolerance and to enable elucidation of the different mechanisms operating, future research should focus on screening a large number of $K$. pomifera genotypes, with four to six salinity treatment levels ranging from 0 to $250 \mathrm{~mm}$ $\mathrm{NaCl}$, and evaluating the traits that were most responsive to increased salinity, such as number of $1^{\circ}$ branches containing $2^{\circ}$ branches, and the number of $2^{\circ}$ branches. Evaluation of additional traits and over additional time points during the experiment will help identify genotypes with a broad spectrum of genes/quantitative trait loci that affect salinity tolerance and can be used to select genotypes for future experiments and breeding. Additionally, salinity tolerance should be tested in field conditions at commercial $K$. pomifera orchards to observe the effects of soil salinity on flowering time, fruit development, and fruit yield.

\section{Literature Cited}

Abassi, M., K. Mguis, Z. Bejaoui, and A. Albouchi. 2014. Morphogenetic responses of Populus $a l b a$ L. under salt stress. J. For. Res. 25:155161.

Al-Rawi, A. and A. Al-Mohemdy. 2001. Effect of water quality on the growth and yield of date palm (Phoenix dactylifera L.). Proceedings of Second International Conference on Date Palms. p. 128-137. United Arab Emirates University, Al-Ain, United Arab Emirates.

Al Hassan, M., M.D.P. López-Gresa, M. Boscaiu, and O. Vicente. 2016. Stress tolerance mechanisms in Juncus: Responses to salinity and drought in three Juncus species adapted to different natural environments. Funct. Plant Biol. 43:949-960.

Alireza, S., Y.B. Awang, A.S. Juraimi, and R. Othman. 2013. Growth and physiological responses of 'Persian' lime and 'Mayer' lemon to salinity stress, p. 755-761. In: F. Massawe, S. Mayes, and P. Alderson (eds.). 2nd International Symposium on Underutilized Plant Species: Crops for the Future-Beyond Food Security.

Andres, Z., J. Perez-Hormaeche, E.O. Leidi, K. Schlucking, L. Steinhorst, D.H. McLachlan, K. Schumacher, A.M. Hetherington, J. Kudla, B. Cubero, and J.M. Pardo. 2014. Control of vacuolar dynamics and regulation of stomatal aperture by tonoplast potassium uptake. Proc. Natl. Acad. Sci. U S A. 111:E1806-E1814.

Australian Bureau of Statistics. 2010. Salinity. 25 Feb. 2017. <http://www.abs.gov.au/ausstats/abs@.nsf/ Lookup/by\%20Subject/1370.0 2010 Chapter Salinity\%20\%286.2.4.4\%29>.

Barragán, V., E.O. Leidi, Z. Andrés, L. Rubio, A. De Luca, J.A. Fernández, B. Cubero, and J.M. Pardo. 2012. Ion exchangers NHX1 and NHX2 mediate active potassium uptake into vacuoles to regulate cell turgor and stomatal function in Arabidopsis. Plant Cell. 24:11271142 .

Ben-Gal, A. 2011. Salinity and olive: From physiological responses to orchard management. Isr. J. Plant Sci. 59:15-28.

Berger, B., B. de Regt, and M. Tester. 2012. Trait dissection of salinity tolerance with plant phenomics. Methods Mol. Biol. 913:399-413.

Cassaniti, C., C. Leonardi, and T.J. Flowers. 2009. The effects of sodium chloride on ornamental shrubs. Scientia Hort. 122:586-593.

Chartzoulakis, K.S. 2005. Salinity and olive: Growth, salt tolerance, photosynthesis and yield. Agr. Water Mgt. 78:108-121.

Clarke, M. 2012. Australian native food industry stocktake. Rural Industries Research and Development Corporation (RIRDC). Report 12/ 066.

Clarke, M. 2013. Native Foods R\&D priorities and strategies 2013 - 2018. Rural Industries Research and Development Corporation (RIRDC). Report 13/023.

Corwin, D.L. and S.R. Grattan. 2018. Are existing irrigation salinity leaching requirement guidelines overly conservative or obsolete? J. Irrig. Drain. Eng. 144:e02518001.

Department of Agriculture and Food. 2016. Water salinity and plant irrigation. 3 Mar. 2017. $<$ https:// www.agric.wa.gov.au/fruit/water-salinity-andplant-irrigation?page $=0 \% 2 \mathrm{C} 0>$

Department of Human Services-South Australia. 1999. EPA-SA, Department of Human Services Environment Protection Agency-Government of South Australia, South Australian Reclaimed Water Guidelines (Treated Effluent). 14 June 2017. $<$ https://www.lga.sa.gov.au/webdata/resources/ files/SA_Reclaimed_Water_Guidlines_-_Treated_Effluent_-_EPA_(22).pdf $>$.

Do, C.M., K.L. Delaporte, and C.J. Schultz. 2017 Benchmarking study of quality parameters of Rivoli Bay selection of Kunzea pomifera (muntries): A new Indigenous crop from Australia. Scientia Hort. 219:287-293.

Do, C.M., L.C. Panakera-Thorpe, K.L. Delaporte, A.E. Croxford, and C.J. Schultz. 2018. Genic simple sequence repeat markers for measuring genetic diversity in a native food crop: A case study of Australian Kunzea pomifera F.Muell. (muntries). Genet. Resources Crop Evol. 65:917-937.

FAO. 2016. AQUASTAT Main Database, Food and Agriculture Organization of the United
Nations (FAO). 25 Mar. 2017. <http://www. fao.org/nr/water/aquastat/data/query/results.html $>$.

Fricke, W. and W.S. Peters. 2002. The biophysics of leaf growth in salt-stressed barley. A study at the cell level. Plant Physiol. 129:374-388.

Garriga, M., C.A. Muñoz, P.D. Caligari, and J.B. Retamales. 2015. Effect of salt stress on genotypes of commercial (Fragaria x ananassa) and Chilean strawberry ( $F$. chiloensis $)$. Scientia Hort. 195:37-47.

Imada, S., N. Iviatsuo, K. Acharya, and N. Yamanaka. 2015. Effects of salinity on fine root distribution and whole plant biomass of Tamarix ramosissima cuttings. J. Arid Environ. 114:84-90.

Jacobsen, S.E., C.R. Jensen, and F. Liu. 2012. Improving crop production in the arid Mediterranean climate. Field Crops Res. 128:34- 47.

Jha, D., N. Shirley, M. Tester, and S.J. Roy. 2010. Variation in salinity tolerance and shoot sodium accumulation in Arabidopsis ecotypes linked to differences in the natural expression levels of transporters involved in sodium transport. Plant Cell Environ. 33:793-804.

Liu, K., H.H. Fu, Q.X. Bei, and S. Luan. 2000. Inward potassium channel in guard cells as a target for polyamine regulation of stomatal movements. Plant Physiol. 124:1315-1325.

Loescher, W., Z.L. Chan, and R. Grumet. 2011. Options for developing salt-tolerant crops. HortScience 46:1085-1092.

Munns, R. 2010. Approaches to identifying genes for salinity tolerance and the importance of timescale. Methods Mol. Biol. 639:25-38.

Munns, R., R.A. James, B. Xu, A. Athman, S.J. Conn, C. Jordans, C.S. Byrt, R.A. Hare, S.D. Tyerman, M. Tester, D. Plett, and M. Gilliham. 2012. Wheat grain yield on saline soils is improved by an ancestral $\mathrm{Na}^{+}$transporter gene. Nat. Biotechnol. 30:360-364.

Munns, R. and M. Tester. 2008. Mechanisms of salinity tolerance. Annu. Rev. Plant Biol. 59:651-681.

Murkute, A.A., S. Sharma, and S.K. Singh. 2005 Citrus in terms of soil and water salinity: A review. J. Sci. Ind. Res. (India) 64:393-402.

Obermeier, C., M.A. Hossain, R. Snowdon, J. Knufer, S. von Tiedemann, and W. Friedt. 2013. Genetic analysis of phenylpropanoid metabolites associated with resistance against Verticillium longisporum in Brassica napus. Mol. Breed. 31:347-361.

Page, T. 2004. The domestication and improvement of Kunzea pomifera (F.Muell.), Rural Industries Research and Development Corporation (RIRDC). Report 03/127.

Parihar, P., S. Singh, R. Singh, V.P. Singh, and S.M. Prasad. 2015. Effect of salinity stress on plants and its tolerance strategies: A review. Environ. Sci. Pollut. Res. Intl. 22:4056-4075.

Passioura, J.B. and R. Munns. 2000. Rapid environmental changes that affect leaf water status induce transient surges or pauses in leaf expansion rate. Funct. Plant Biol. 27:941-948.

Qadir, M., E. Quillerou, V. Nangia, G. Murtaza, M. Singh, R.J. Thomas, P. Drechsel, and A.D. Noble. 2014. Economics of salt-induced land degradation and restoration. Nat. Resour. Forum 38:282-295.

Roy, S.J., S. Negrao, and M. Tester. 2014. Salt resistant crop plants. Curr. Opin. Biotechnol. 26:115-124.

Ryder, M., Y. Latham, and B. Hawke. 2008. Cultivation and harvest quality of native food crops. Rural Industries Research and Development Corporation (RIRDC). Report 08/019.

Schultz, C.J., D.J. Apps, T.E. Johnson, and S.E.P. Bastian. 2009. Testing consumer acceptability of new crops: An integrated sensory and 
marketing approach using muntries, an Australian native berry. Food Austral. 61:335-341.

Shabala, S. and I. Pottosin. 2014. Regulation of potassium transport in plants under hostile conditions: Implications for abiotic and biotic stress tolerance. Physiol. Plant. 151:257-279.

Sultanbawa, F. 2016. Cultivation of muntries (Kunzea pomifera F. Muell.), p. 127-131. In: Y. Sultabawa and F. Sultabawa (eds.).
Australian Native Plants: Cultivation and Uses in the Health and Food Industries. CRC Press, Boca Raton, FL

Tripler, E., U. Shani, Y. Mualem, and A. Ben-Gal. 2011. Long-term growth, water consumption and yield of date palm as a function of salinity. Agr. Water Mgt. 99:128-134.

U.S. Department of Agriculture. 2017. Salt tolerance databases, United States Department of
Agriculture Agricultural Research Service. 25 Mar. 2017. <https://www.ars.usda.gov/pacificwest-area/riverside-ca/us-salinity-laboratory/ docs/research-databases/>

Wu, H.H., L. Shabala, X.H. Liu, E. Azzarello, M. Zhou, C. Pandolfi, Z.H. Chen, J. Bose, S. Mancuso, and S. Shabala. 2015. Linking salinity stress tolerance tissue-specific $\mathrm{Na}^{+}$sequestration in wheat roots. Front. Plant Sci. 6:71. 